\title{
ELECTRICALLY DRIVEN COMBUSTION NEAR THE PLANE WALL IN A SUPERSONIC DUCT
}

\author{
S. Leonov ${ }^{1}$, D. Yarantsev ${ }^{1}$, and V. Sabelnikov ${ }^{2}$ \\ ${ }^{1}$ Joint Institute for High Temperatures \\ Russian Academy of Sciences \\ Izhorskaya Str. 13 b2, Moscow 125412, Russia \\ ${ }^{2}$ ONERA/DEFA/EFCA \\ Fort de Palaiseau, Chemin de la Hunire 91761, France
}

The ultimate objective of this work was to enhance the performance of air-breathing engines in transient modes. The paper presents the results of laboratory-scale experiments on ignition of nonpremixed fuelair composition in high-speed flow by a near-surface electrical discharge. The experiments were fulfilled under conditions of model supersonic combustor on the plane wall without any mechanical flameholder. The ignition and flameholding of hydrogen-air and ethylene-air compositions were demonstrated for direct fuel injection into the flow at low $\left(T_{0}=300-750 \mathrm{~K}\right)$ gas temperature. The deposited power was $W_{\mathrm{pl}} / H_{\mathrm{tot}}<2 \%-5 \%$ of flow total enthalpy. The power threshold of fuel ignition over the plane wall was measured by variation of power deposition and fuel mass flow rate. The combustion completeness was estimated to be reasonably high, $\eta>0.9$, with both hydrogen and ethylene fuels under optimal conditions.

\section{INTRODUCTION}

The concept of Plasma-Induced Ignition and Plasma-Assisted Combustion is considered on the basis of three main ideas: the gas heating/excitation by the discharge, fuel-air mixing intensification, and flow structure control in the vicinity to the reaction zone [1-3]. The experimental evidences of the plasma-based fuel ignition and flameholding in subsonic and supersonic flows were obtained by several groups, for example, [4-11]. The results of a combined experimental and theoretical study of basic properties of the transverse filamentary electrical discharge on the plane wall in a supersonic flow and the use of such a discharge

This is an Open Access article distributed under the terms of the Creative Commons Attribution-Noncommercial License 3.0, which permits unrestricted use, distribution, and reproduction in any noncommercial medium, provided the original work is properly cited. 
as a new type of flameholder were reported in $[12,13]$. The supersonic combustor performance under a variety of conditions is analyzed, for example, in [14].

The effective operation of a scramjet over a wide range of flow Mach numbers is one of technical challenges in the design of hypersonic vehicles powered by air-breathing engines. The most promising design is a scramjet possessing a flexible gasdynamic configuration (including inlet, injection system, combustor, and nozzle) depending on flight Mach number and altitude. Unfortunately, this approach is not properly supported by technical issues: materials, gears, etc. A commonly discussed trade-off consists of a fixed geometrical configuration based on some "characteristic" Mach number of operation. Presumably, this sort of design will demonstrate worse performance for both lower and higher Mach numbers.

To improve an overall capability of a scramjet with fixed geometry of the duct, some additional methods could be applied, for instance, staged fuel injection, additional flameholding at low temperature (plasma as well), and a few others. The penalty of such a philosophy is an increase in total pressure losses and, as a consequence, a decrease in the specific impulse and thrust coefficient. This work proposes an advanced approach to expand the operational domain of the scramjet to offdesign values of Mach number at a fixed geometry of the gasdynamic duct. It is based on the experimental results in the field of so-called "Plasma-Assisted Combustion" obtained during past years in JIHT RAS [13, 15, 16]. The following principally important results have been obtained:

- the benefit of plasma generation in the flow lies not only in heating and active media production, but also in modification of supersonic flow structure, including artificial separation, vorticity, etc. In proper modes, plasma localization and parameters in the reacting flow are self-adjusted with the zones of chemical reaction. These feedbacks are important features of active flame control by electrical discharges; and

- in case of hydrocarbon fueling and low temperature, flame stabilization by nonequilibrium plasma occurs as a two-stage process. At the first stage, the plasma induces fuel reforming, which may be simplified as production of $\mathrm{H}_{2}, \mathrm{CH}_{2} \mathrm{O}$, and $\mathrm{CO}$. In spite of bright luminescence, this zone does not experience a significant temperature and pressure increase. This so-called "cool flame" [17-19] appears as a source of active chemical species initiating (under favorable conditions) the second stage of "normal" combustion, characterized by main temperature and pressure rise.

Prospectively, the utilization of this method might lead to a reduction in total pressure losses under nonoptimal conditions, enhancement in operation stability, and, consequently, expansion of the limitations in scramjet operability as shown schematically in Fig. 1. 


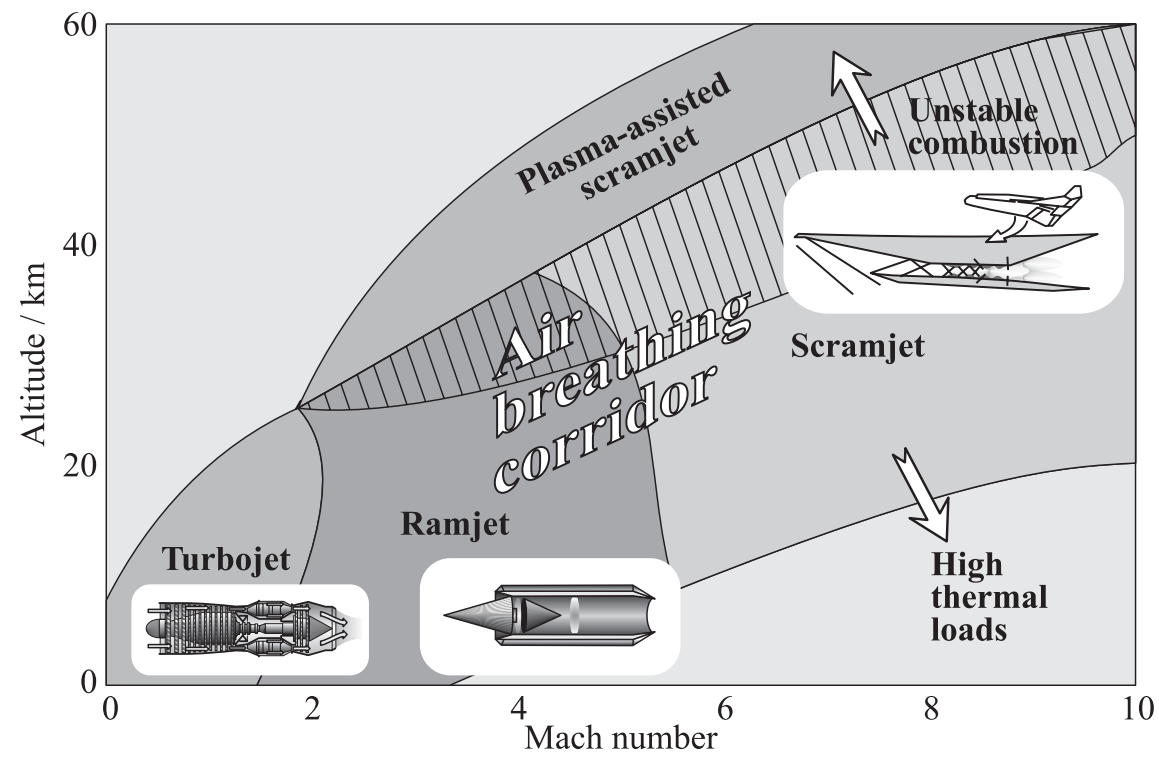

Figure 1 Expansion of air-breathing corridor due to plasma application. Qualitative scheme

\section{EXPERIMENTAL FACILITY}

The experimental facility PWT-50H of JIHT $[12,13]$ was used for the tests on ignition and flameholding. Hydrogen and ethylene were injected directly into the $\mathrm{M}=2$ flow from the wall or to a fixed zone of separation (backward facing step and cavity). These experiments were characterized by the following parameters: test section dimensions $72 \times 72 \mathrm{~mm}$; Mach number of the undisturbed flow $\mathrm{M}=1.9-2$; static pressure $P_{\text {st }}=100-150$ Torr; typical air flow rate $G_{\text {air }}$ $=0.6-0.9 \mathrm{~kg} / \mathrm{s}$; typical fuel mass flow rate (hydrogen or ethylene) $G_{\text {fuel }}$ $=0.1-6 \mathrm{~g} / \mathrm{s}$; discharge power $W_{\mathrm{pl}}=1-10 \mathrm{~kW}$; and test duration $t<0.5 \mathrm{~s}$. A principal layout of the facility and the test section arrangement are shown in Fig. 2.

The air heater was built according to the combined scheme. The conceptdesign of the air heater included the arc chamber (up to 50-kilowatt power) and combustion chamber (prechamber of the PWT-50H in this particular case). After admixing the cold air, the stagnation temperature of the airflow could be varied in the range $T_{0}=300-750 \mathrm{~K}$.

The facility was equipped with pressure transducers (16 ports), a Schlieren system, a Schlieren/streak-camera system, devices for optical and spectroscopic observations, current--voltage sensors, laser-absorption spectroscopy of water vapors, station of chemical analysis of exhaust gases, etc. 


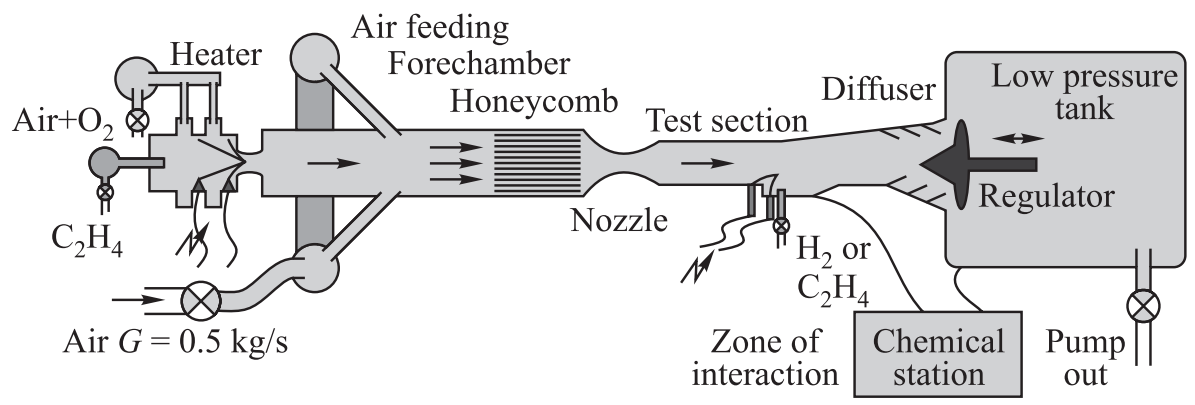

Scheme 1

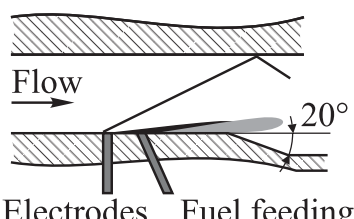

Scheme 2

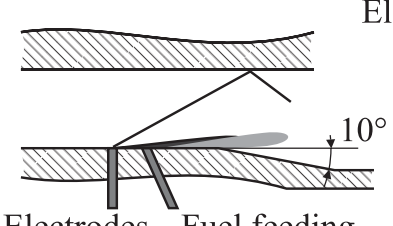

Scheme 3

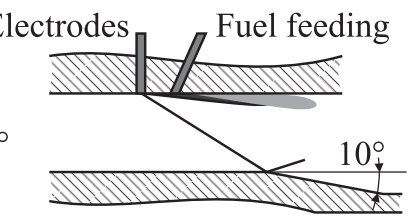

Electrodes Fuel feeding

Electrodes Fuel feeding

Figure 2 Layout of the PWT-50H facility and three main schemes of the test section arrangement

\section{DISCHARGE CHARACTERIZATION}

The major properties of the near-surface quasi-direct-current (DC) electrical discharge were described in $[12,13,20]$. The discharge appeared in the form of oscillating plasma filaments as shown in Fig. $3 a$. Initial electrical breakdown occurred not far from the electrodes. The individual filaments were blown down by the main flow at the velocity a bit less than the core value. The frequency of oscillations depended on the flow velocity, interelectrode gap, and parameters of power supply. In most cases, this value was $F=10-30 \mathrm{kHz}$ under the experimental conditions. The power release was in a range $W_{\mathrm{pl}}=3-17 \mathrm{~kW}$ and was controlled by changing the electrical current $I_{\mathrm{pl}}=2-20$ A. When the current was increased by a factor of 10 , the voltage decreased, but only by a factor of 5 . This resulted in the rise of power about twice. Such a method led to some variation in the reduced electric field $E / N$ that could be important for understanding some features of interaction. The nonequilibrium plasma (characterized by high $E / N$ level) could be more effective in terms of fast fuel ignition [1, 2].

At low current, the discharge was unstable, while at high current, the erosion of electrode was significant. Temperature measurements based on the optical emission spectroscopy of the $\mathrm{N}_{2}$ second-positive system (i. e., $\mathrm{C}^{3} \Pi \leftarrow \mathrm{B}^{3} \Pi$ emission) yielded a rotational temperature of $T_{r}=3500 \pm 300 \mathrm{~K}$, independent of the power release from the discharge under conditions of this experiment. The 


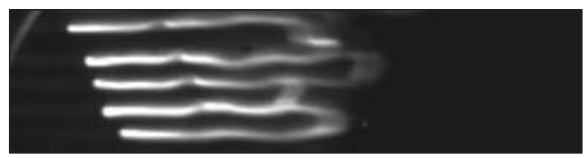

(a)

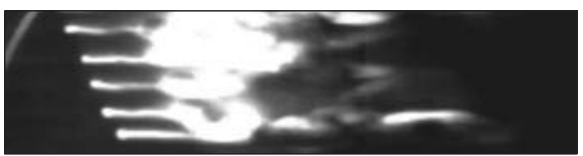

(b)

Figure 3 The discharge appearance: $(a)$ photo in scheme 3, flow from left to right; and $(b)$ discharge under ethylene injection

time of rotational-translational relaxation was rather small under considered conditions. Therefore, the rotational and translational temperatures were equal, i. e., $T_{r} \approx T_{g}$ with high accuracy. This measurement showed the maximum gas

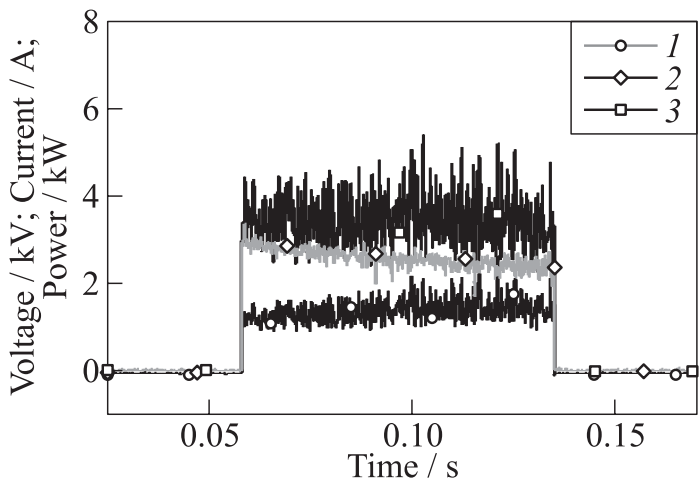

(a)

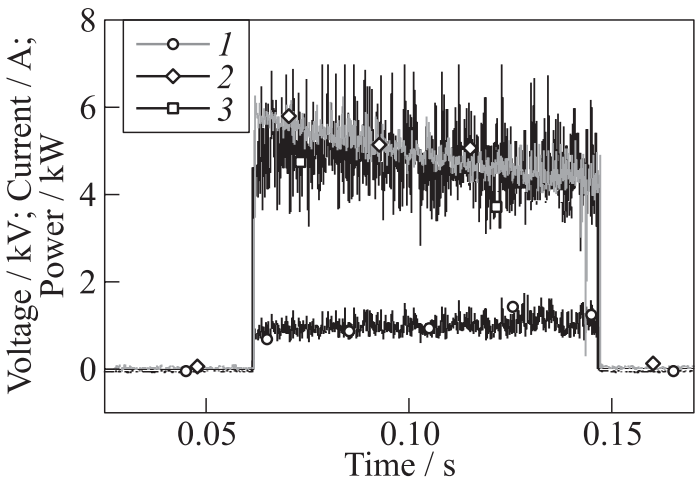

(b)

Figure 4 Typical oscillograms for high-voltage ( $\left.W_{\mathrm{av}}=3.55 \mathrm{~kW}\right)(a)$ and high-current $\left(W_{\mathrm{av}}=4.88 \mathrm{~kW}\right)(b)$ modes of discharge operation: 1 - voltage; 2 - current; and 3 - power 
temperature in the plasma filament, which occupied only a small gas volume. The averaged temperature elevation did not exceed $\Delta T_{g}=30 \mathrm{~K}$ in all operation modes. Typical oscillograms of the two regimes are shown in Fig. 4.

The fuel was injected through 5 circular $(d=3.5 \mathrm{~mm})$ orifices, all in a row across the span, and inclined at $25^{\circ}$ from the normal to the upstream direction. The row of injectors was located $15 \mathrm{~mm}$ downstream from the row of electrodes, in the same ceramic block. Each injector was in line with an electrode in the configuration that included 5 electrodes. The fuel mass flow rate was balanced between the orifices using a fuel plenum. Fuel injection was started prior to the discharge initiation and switched off after completion of the discharge. Typically, the fuel injection continued 10-20 ms after the discharge to observe whether the flame was held or extinguished.

\section{EXPERIMENTAL RESULTS}

A main criterion for detecting the effect of discharge was a rise of the static pressure in the combustion zone. Fuel ignition and flameholding were studied experimentally with both hydrogen and ethylene.

In scheme 1 (see Fig. 2), the primary ignition took place behind the inclination (no initial separation). Subsequently, the flamefront propagated upstream toward the discharge location and stabilized at a location that depended on fuel mass flow rate and discharge power. The data below illustrate the details of plasma-fuel-flow interaction: Schlieren images in Fig. 5 and pressure distributions in Figs. 6 and 7 . The most representative measurement in these experiments was the static pressure in the midpoint of the inclined plane (PW2). In the range of $G_{\mathrm{H}_{2}}=0.4-0.6 \mathrm{~g} / \mathrm{s}$, the hydrogen flame position was sensitive to the fuel flow rate and discharge power which clearly follows from Fig. 6 showing the dependence of pressure on hydrogen flow rate and discharge power in different measuring points. The data similar with Fig. $6 b$ are presented

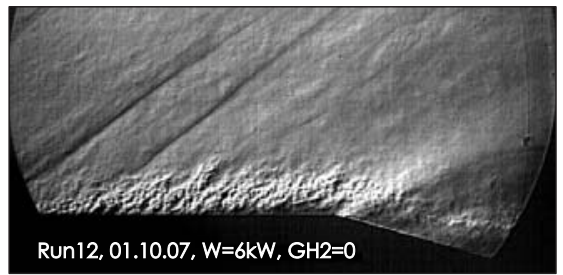

(a)

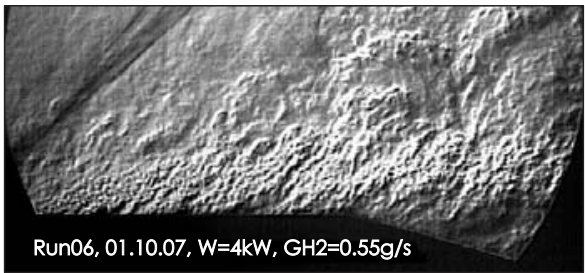

(b)

Figure 5 Schlieren pictures in two cases: $(a)$ no combustion (effect of discharge at $W_{\mathrm{pl}}=W_{\max }=6 \mathrm{~kW}$ ); and (b) "optimal" flameholding (no choking, intense combustion) 


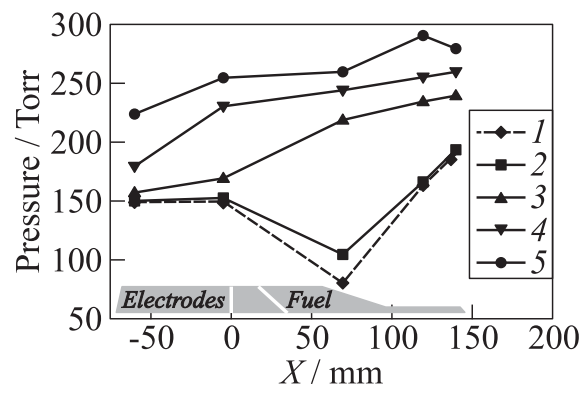

(a)

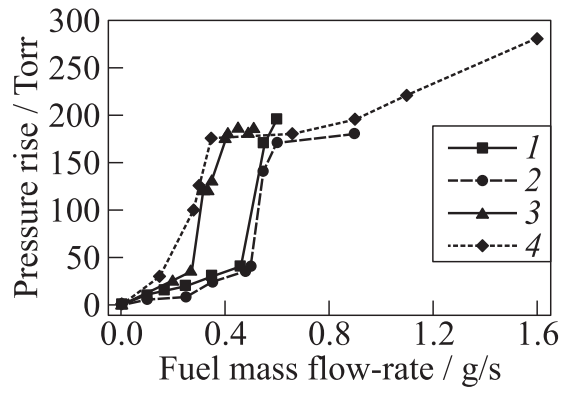

(b)

Figure 6 Static pressure distributions for varying hydrogen flow rates $(1-$ no discharge, no fuel; $2-G=0.45 \mathrm{~g} / \mathrm{s} ; 3-0.55 ; 4-0.60 ;$ and $5-G=0.90 \mathrm{~g} / \mathrm{s})$ at constant discharge power $W=4 \mathrm{~kW}(a)$; static pressure vs. hydrogen flow rate at various discharge powers $(1-W=3.4 \mathrm{~kW} ; 2-4 ; 3-4.7$; and $5-W=5.6 \mathrm{~kW})$ in the point $X=60 \mathrm{~mm}(b)$

in Fig. 7 for ethylene at $W_{\mathrm{pl}} \geq 6 \mathrm{~kW}$, when combustion was detected.

The experiments showed that ethylene was more difficult to ignite (greater discharge power was required). Despite of the "area relief" provided by the inclined bottom wall, thermal choking was observed in tests with hydrogen at $G_{\mathrm{H}_{2}}>1 \mathrm{~g} / \mathrm{s}$, but not in tests with ethylene.

After analyzing the flow patterns, it was concluded that the most promising configuration is scheme 3 because of the plane wall in the combustion zone. To support this conclusion, the Schlieren pictures were

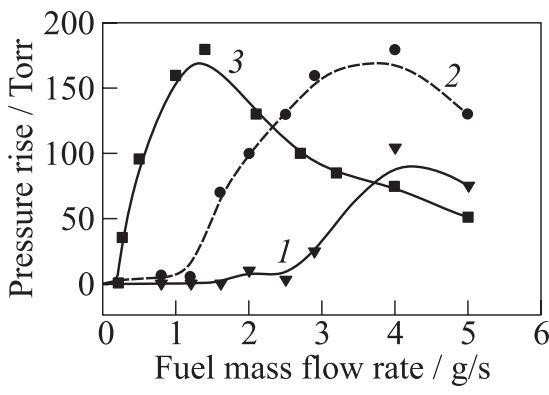

Figure 7 Static pressure rise vs. ethylene flow rate at various fuel feed: $1-X$ $=-10 \mathrm{~mm}, W=6 \mathrm{~kW} ; 2-X=60 \mathrm{~mm}$, $W=6 \mathrm{~kW}$; and $3-X=60 \mathrm{~mm}, W$ $=8 \mathrm{~kW}$ recorded using the additional window in the test section. Figure 8 illustrates the details of plasma-fuel-flow interaction in terms of the Schlieren images of ethylene combustion. Moreover, Fig. 9 presents pressure distributions in the test with ethylene. As is seen in the test with ethylene, the combustion zone is located far downstream from the discharge zone and fuel feed.

The position of the flame front was visualized by the novel Schlieren-streak technique. At a constant fuel flow rate, the flame front could be controlled by the discharge power in accordance with a qualitative law: the higher the power, the shorter the distance between the point of fuel injection and the flame front. Another important feature was that at all test conditions with both fuels, 


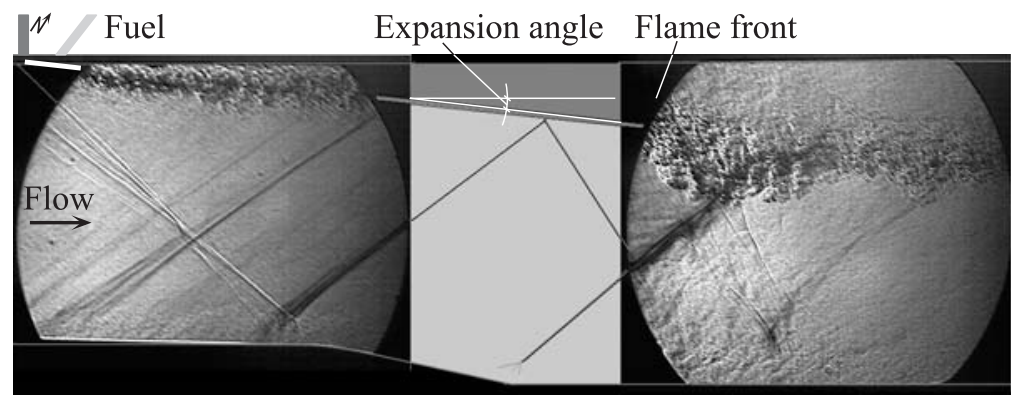

Figure 8 Schlieren pictures of ethylene combustion. Combination of images from two windows

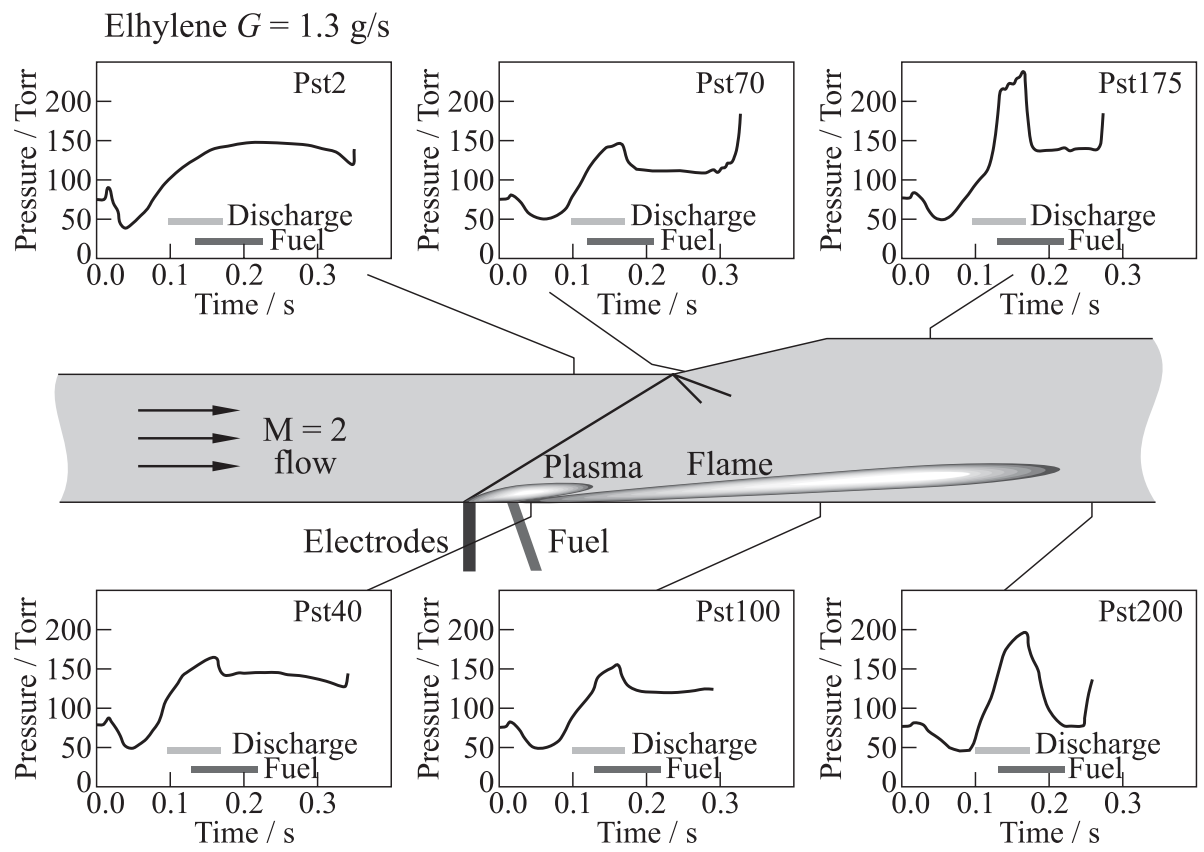

Figure 9 Static pressure distributions at ethylene injection. Discharge power $W_{\mathrm{pl}}$ $=12 \mathrm{~kW}$. Top and bottom sides are reversed

there was no combustion without discharge. Moreover, discharge switching off promptly led to flame extinction.

In the further analysis, the most representative measuring points were $P_{\text {st }} 40$ - the static pressure $40 \mathrm{~mm}$ downstream from the electrodes; $P_{\mathrm{st}} 100$ $100 \mathrm{~mm}$ downstream; and $P_{\mathrm{st}} 175-175 \mathrm{~mm}$ downstream on the opposite wall. 


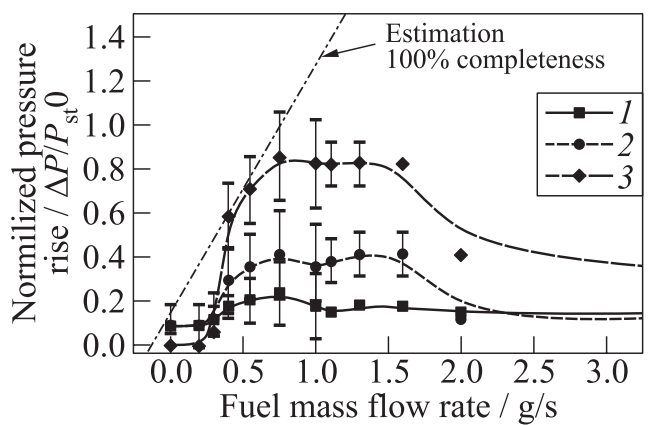

Figure 10 Static pressure vs. ethylene mass flow rate in various cross sections: 1 $P_{\mathrm{st}} 40 ; 2-P_{\mathrm{st}} 100 ;$ and $3-P_{\mathrm{st}} 175$

Figure 10 shows the dependence of pressure in these points on the ethylene flow rate. It is clearly seen that for rich mixtures, the ethylene is more difficult to ignite (a greater discharge power is required) and the flame front shifts downstream of the place of interaction. The combustion completeness is reduced as well.

Based on the observations, the following 2-stage scheme of flameholding can be proposed. In zone 1, the "cold" combustion takes place, which is characterized by plasma-induced fuel conversion and relatively small power release; in zone 2 , combustion is completed or almost completed with a high level of energy release. Due to this approach, the role of plasma is in the generation of large amount of active species for launching the first stage. The typical length of the first zone was $X=50-150 \mathrm{~mm}$ in the particular test that is equivalent to the combustion induction time $\tau_{\text {ind }}=0.1-0.3 \mathrm{~ms}$. Currently, this scheme is under the detailed analysis.

\section{Scheme of Electrically Controlled High-Speed Combustor}

As it can be noted based on the data discussed above, the metered fuel mass flow rate resulted in an equivalence ratio (ER) less than 0.1 , estimated by the total air flow through the duct. The reason for this is quite obvious: under condition of low gas temperature and effective combustion of the injected fuel, the relative pressure rise is large at high fuel flow rate. In practice, the pressure rise leads to thermal choking of the duct or to the development of instabilities [13] that, in turn, reduce combustion completeness. To resolve this problem, the fuel can be burned step by step in a controllable manner. A number of local zones of combustion can be adjusted to optimize the performance.

The concept of supersonic flameholding and combustion control by the plasma of electrical discharge is based on the results discussed above and is composed of several issues [20]: 


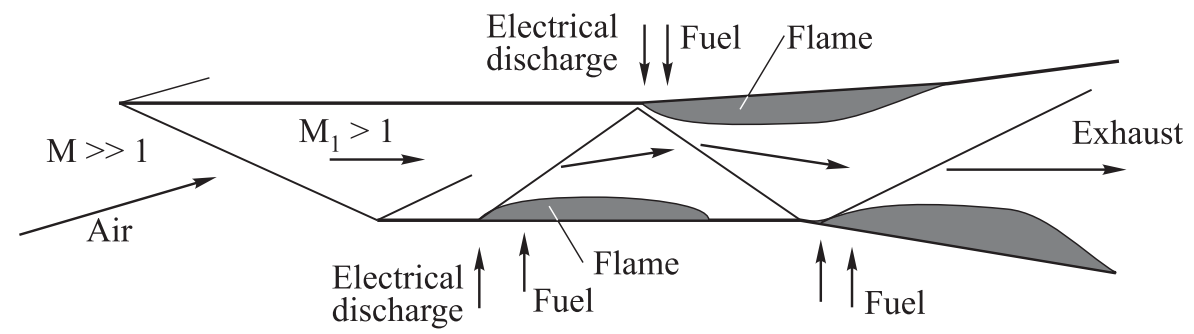

Figure 11 Scheme of electrically controlled low-temperature supersonic combustor

- instead of fixed separation zones based on mechanical elements (wallstep, cavity, pylon, strut, etc.), the area of local separation could be created by a near-surface electrical discharge plus jets of fuel based on flush-mounted electrodes and orifices;

- the plasma generator and fuel injector could be composed together as a single unit utilized for fuel ignition, flameholding, and combustion control; and

- location of these units along the duct, their activation (and switching off), and the magnitude of impact are chosen based on the maximal engine efficiency and steered by active feedbacks.

Based on the experimental data, a scheme of supersonic combustor is proposed as shown in Fig. 11. Local combustion zones are multiple and distributed in wall-fueled sections supported by electrical discharges. The duct expansion is then adjusted with respect to those zones of intense energy release. This scheme possesses an important advantage: much improved low-temperature operation and thus a greater prospect for practical devices.

\section{CONCLUDING REMARKS}

Control of ignition in aircraft jet engines is of crucial importance for their performance over a wide range of operation parameters, such as altitude, flight speed, and thrust. Reduction of the ignition delay time, improvements in flameholding and flame stability, prevention of flame blowoff, and extension of fuel flammability limits are some of the key technical issues in this field. In this paper, the additional mechanisms (electrical discharges excited in the flow) were described as the promising approaches competing the mechanical methods of flameholding. The capabilities of electronically controlling the claimed effects are demonstrated experimentally.

The impact of the transverse discharge on flameholding in the $\mathrm{M}=2$ flow along a plane wall has been studied. The main physical effects observed are 
that the discharges heat the gas and generate high concentrations of radicals thus modifying the flow field and inducing separation. The maximum effect at a minimal power deposition can be realized with in situ plasma generation, nonequilibrium composition, and a nonuniform discharge structure. Such an approach has been demonstrated in different geometrical configurations.

Ignition and flameholding were realized for $\mathrm{H}_{2}$ and $\mathrm{C}_{2} \mathrm{H}_{4}$ as fuels in a combustor with a plane wall using a transverse electrical discharge at relatively low power deposition $(<2 \%$ of flow enthalpy). The power threshold for hydrogen flameholding was measured to be $W_{\mathrm{pl}}<3 \mathrm{~kW}$; with ethylene, it was measured to be $W_{\mathrm{pl}} \geq 4 \mathrm{~kW}$. The combustion completeness was estimated to be reasonably high, $\eta>0.9$, with both hydrogen and ethylene under optimal conditions.

The ignition effect of the gas discharge was compared for different levels of power, power density, and reduced electrical field (characterizing the deviation from equilibrium for the discharge). Here, it was found that the effectiveness of the flameholding was determined primarily by the level of power deposition and by the power density. In these experiments, the effect of reduced electric field was not an important factor. In comparison to tests with hydrogen, the main difference of tests with ethylene was the absence of thermal choking even at the maximum discharge power $W_{\mathrm{pl}}>10 \mathrm{~kW}$. Furthermore, the completeness of ethylene combustion decreased with fuel mass flow rate.

The concept of two-stage plasma assistant ignition and flameholding was formulated based on the experimental observations. Currently, this concept is under detailed analysis.

\section{ACKNOWLEDGMENTS}

This experimental study was funded through EOARD-ISTC project \#3057p (special thanks to Dr. J. Tishkoff and Dr. C. Carter). Some part of this work was also supported by the Russian Academy of Sciences (coordinator Academician V. E. Fortov).

\section{REFERENCES}

1. Leonov, S. B., D. A. Yarantsev, A.P. Napartovich, and I. V. Kochetov. 2006. Plasma-assisted combustion of gaseous fuel in supersonic duct. IEEE Trans. Plasma Sci. 34(6):2514-25.

2. Starikovskaia, S. M. 2006. Plasma assisted ignition and combustion. J. Phys. D, Appl. Phys. 39(16):R265-R99.

3. Jacobsen, L.S., C.D. Carter, R. A. Baurle, T. Jackson, S. Williams, J. Barnett, C.-J. Tam, D. Bivolaru, and S. Kuo. 2008. Plasma-assisted ignition in scramjets. J. Propul. Power 24(4):641-54. doi:10.2514/1.27358. 
4. Takita, K. 2002. Ignition and flame-holding by oxygen, nitrogen and argon plasma torches in supersonic airflow. Combust. Flame 128:301.

5. Wang F., J. B. Liu, J. Sinibaldi, C. Brophy, A. Kuthi, C. Jiang, P. Ronney, and M. A. Gundersen. 2005. Transient plasma ignition of quiescent and flowing air/fuel mixtures. IEEE Trans. Plasma Sci. 33(2):844-49.

6. Marcum, S. D., and B. N. Ganguly. 2005. Electric-field-induced flame speed modification. Combust. Flame 143(1):23-36.

7. Ombrello, T., X. Qin, Y. Ju, A. Gutsol, A. Fridman, and C. Carter. 2006. Combustion enhancement via stabilized piecewise nonequilibrium gliding arc plasma discharge. AIAA J. 44(1):142-50.

8. Pilla, G., D. Galley, D. A. Lacoste, F. Lacas, D. Veynante, and C. O. Laux 2006. Stabilization of a turbulent premixed flame using a nanosecond repetitively pulsed plasma. IEEE Trans. Plasma Sci. 34(6):2471-77.

9. Lou, G., A. Bao, M. Nishihara, S. Keshav, Y. G. Utkin, J. W. Rich, W. R. Lempert, and I. V. Adamovich. 2007. Ignition of premixed hydrocarbon-air flows by repetitively pulsed, nanosecond pulse duration plasma. Proc. Combust. Inst. 31(2):332734.

10. Goldfeld, M. A., S. S. Katsnelson, and G. A. Pozdnyakov. 2007. Plasma initiation of the chemical reactions in a supersonic stream on the example of hydrogen and natural gas combustion reaction. 8th Symposium (International) on Experimental and Computational Aerothermodynamics of Internal Flows Proceedings. Lyon, France. ISAIF8-0016.

11. Hyungrok Do, M. G. Mungal, and A. M. Cappelli. 2008. Jet flame ignition in a supersonic crossflow using a pulsed nonequilibrium plasma discharge. IEEE Trans. Plasma Sci. 36(6):2918-23.

12. Leonov, S., and D. Yarantsev 2008. Near-surface electrical discharge in supersonic airflow: Properties and flow control. J. Propul. Power 24(6):1168-81.

13. Leonov, S., C. Carter, and D. Yarantsev 2009. Experiments on electrically controlled flameholding on a plane wall in supersonic airflow. J. Propul. Power 25(2):289-98.

14. Sabel'nikov, V.A. 1997. Supersonic turbulent combustion of nonpremixed gasesstatus and perspectives. In: Advanced computation \& analysis of combustion. Eds. G. D. Roy, S. M. Frolov, and P. Givi. Moscow: ENAS Publ. 208-37.

15. Leonov, S., and V. Sabelnikov 2008. Electrically driven supersonic. 6th Symposium (European) on Aerothermodynamics for Space Vehicles Proceedings. Versailles, France.

16. Leonov, S. B., D. A. Yarantsev, and C. Carter 2008. Transversal electrical discharge as a new type of flameholder. AIAA Paper No. 2008-2675.

17. Sokolik, A. S. 1940. Self-ignition and combustion in gases. UFN. XXIII(3):209-50. [In Russian.]

18. Kim, W., M. G. Mungal, and M.A. Cappelli. 2008. Formation and role of cool flames in plasma-assisted premixed combustion. Appl. Phys. Lett. 92:051503.

19. Kim, W., M. G. Mungal, and M. A. Cappelli. 2010. The role of in situ reforming in plasma enhanced ultra lean premixed methane/air flames. Combust. Flame $157: 374-83$.

20. Leonov, S. B., C. Carter, K. V. Savelkin, V. N. Sermanov, and D. A. Yarantsev. 2008. Experiments on plasma-assisted combustion in $\mathrm{M}=2$ hot test-bed PWT50H. AIAA Paper No. 2008-1359. 